\title{
Getting the message across. An August bank holiday long ago
}

Public heath and awareness campaigns have a luminous history. Much still needs to be done. The association between ill health and deprivation now has an acceptance that was not too long ago carefully suppressed in the UK. We remember 'The Black Report', ' which showed that the health of the nation has improved, but the improvement has not been equal across all social classes, and that gap in inequalities of health between lower and higher social classes is widening. Published by the Department of Health and Human Services in 1980, the then UK government made the report public on the August bank holiday weekend and printed only 260 copies. Nevertheless, its impact has been huge, and not just in the UK. ${ }^{2}$

Otolaryngologist head and neck surgeons have long been aware of this association and the effects that deprivation can have. The case for public awareness seems strong. The paper from Humber and Yorkshire Coast Cancer Network investigates their public health campaign on croaky voice and the impact it had on the stage of presentation of laryngeal cancer. ${ }^{3}$ They show that the impact was limited and that the most deprived wards in their region have the highest incidence of laryngeal cancer. They accept that public health campaigns are complex processes, and a more effective campaign may improve outcomes, but the message is stark.

Jahn's article highlights the association between benign positional vertigo and endolymphatic hydrops in the management of patients with vertigo. ${ }^{4}$ He uses statistical data on epidemiology to make the point and a hypothesis to explain the association. This association is known; whether the hypothesis offered will stand the test of time remains to be seen. It is nevertheless plausible and makes sense.

Andrews and colleagues' paper on the assessment of nasal patency shows that the overwhelming majority of surveyed UK ENT surgeons use the clinical misting pattern test rather than the objective peak nasal inspiratory flow measure. ${ }^{5}$ They emphasise the need for a simple, non-invasive device that would objectively measure airflow during physiological resting. The problems in obtaining standard reference values in the assessment of nasal patency are known. ${ }^{6}$

Crosbie and colleagues' investigated the association between sinonasal anatomical variants and the risk of developing orbital cellulitis and associated complications in children with acute rhinosinusitis. ${ }^{7}$ Their results show that anatomical variants do not predispose these children to orbital cellulitis or other complications.

\section{MUSHEER HUSSAIN EDWARD FISHER ROBIN YOUNGS \\ JONATHAN FISHMAN \\ Senior Editors}

References

1 Department of Health and Human Services. Inequalities in Health: Report of a Research Working Group. London: DHHS, 1980

2 Richmond C. Sir Douglas Black. BMJ 2002;325:661

3 Mistry SG, Jose J, Allgar V. Did the 'croaky voice' public health campaign have any impact on the stage of laryngeal cancer at presentation in 84 cases from the Humber and Yorkshire Coast Cancer Network? J Laryngol Otol 2017;131:736-9

4 Jahn AF. Benign positional vertigo and endolymphatic hydrops: what is the connection? J Laryngol Otol 2017;131:658-60

5 Andrews P, Joseph J, Li CH, Nip L, Jacques T, Leung T. A UK survey of current ENT practice in the assessment of nasal patency. J Laryngol Otol 2017;131:702-6

6 Moore M, Eccles R. Normal nasal patency: problems in obtaining standard reference values for the surgeon. J Laryngol Otol 2012; 126:563-9

7 Crosbie RA, Clement WA, Kubba H. Paediatric orbital cellulitis and the relationship to underlying sinonasal anatomy on computed tomography. J Laryngol Otol 2017;131:714-8 